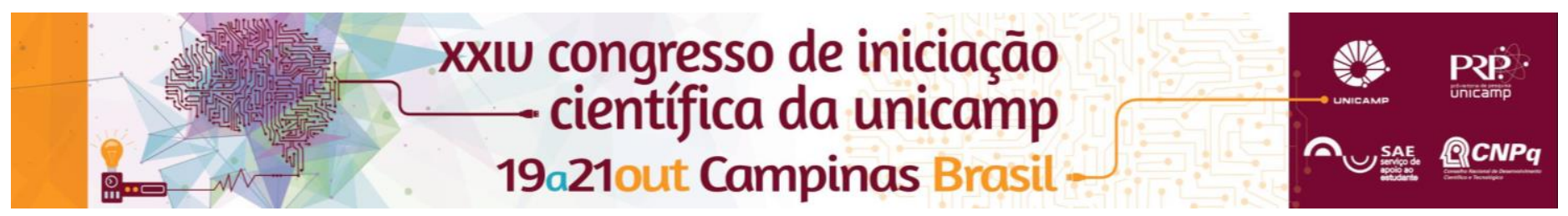

\title{
Fundamentos do Projeto de Interfaces Cérebro-Computador Baseadas em Imaginação de Movimento
}

\author{
Maria B. Kersanach*, Luisa F. S. Uribe, Thiago B. S. Costa, Romis Attux.
}

\begin{abstract}
Resumo
Neste trabalho, apresenta-se uma interface cérebro-computador baseada em imaginação de movimento e analisa-se seu desempenho. A interface tem por fundamentos atributos espectrais e um classificador linear, e realiza um processo de seleção de eletrodos baseado em um wrapper progressivo. Os resultados mostram que a estratégia adotada leva a um bom desempenho se comparada à literatura da área.
\end{abstract}

\section{Palavras-chave: \\ Interfaces Cérebro-Computador, Processamento de Sinais, Inteligência Computacional.}

\section{Introdução}

Interfaces cérebro-computador (BCls, do inglês braincomputer interfaces) são dispositivos que buscam traduzir intenções de um usuário a partir de vias biologicamente não convencionais ${ }^{1}$. Tipicamente, isso é feito através de sinais de eletroencefalografia (EEG), partindo de um determinado paradigma de estimulação do usuário. Neste trabalho, foi projetada uma $\mathrm{BCl}$ baseada no paradigma de imaginação de movimento. Nela, o usuário transmite sua intenção (um bit de informação) ao imaginar o movimento da mão direita ou esquerda, sendo os padrões gerados em seu EEG (especialmente na região do córtex motor) analisados para reconhecer o comando desejado.

O sistema foi desenvolvido em MATLAB, e a aquisição dos sinais se deu com um sistema baseado em eletrodos secos g.SAHARAsys e em um amplificador g.USBamp (GTEC). As aquisições foram aprovadas pelo comitê de ética da UNICAMP (protocolo 791/2010), e se deram em 20 sessões de $8 \mathrm{~s}$ para cada atividade de imaginação de mão direita, esquerda e repouso. A frequência de amostragem foi de $256 \mathrm{~Hz}$, e foram criadas janelas de 3 s com sobreposição de $0,5 \mathrm{~s}$. As bandas utilizadas para representar o espectro de potência do sinal (produzindo os atributos de classificação) foram de 8 a 12 Hz, 12 a 16 $\mathrm{Hz}$ e 16 a $20 \mathrm{~Hz}$.

\section{Resultados e Discussão}

O pré-processamento se dá por meio do uso de um filtro espacial de referência comum (CAR, do inglês common average reference), e a análise espectral é feita por meio do periodograma de Welch. Na etapa de classificação, fez-se uso de um classificador linear baseado em mínimos quadrados².

São escolhidas $70 \%$ das sessões para treinamento do classificador e $30 \%$ das sessões para teste. A escolha dos eletrodos se dá por meio de um wrapper progressivo $^{2}$, o qual utiliza o próprio classificador para determinar os canais de maior relevância. A característica progressiva é interessante do ponto de vista de custo computacional e, como será visto adiante, é adequada ao problema.

Devido ao limite de espaço, serão apresentados apenas os resultados de um dos usuários que testaram a interface, um indivíduo saudável, de 20 anos de idade e do sexo feminino, que não foi submetido a treinamento prévio.

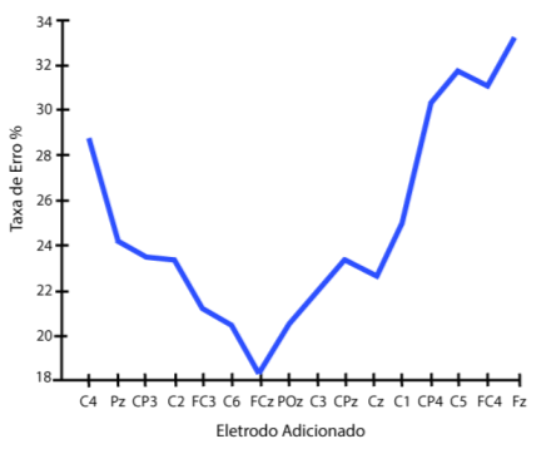

Figura 1. Taxas de Erro para Subconjuntos de Eletrodos

A Figura 1 mostra que, para a sessão enfocada, a interface teve uma boa taxa mínima de erro (da ordem de $18 \%$ ), e revela com clareza a importância do processo de seleção de atributos. Note, por exemplo, que o uso de todos os eletrodos disponíveis levaria a uma taxa de erro superior a $30 \%$. O conjunto ótimo obtido foi composto pelos canais C4, Pz, CP3, C2, FC3, C6 e FCz. A média das taxas de erro para este sujeito, em quatro sessões, é de $15,7 \%$, com desvio padrão de $5,2 \%$. Os resultados são compatíveis com boas abordagens da literatura ${ }^{3}$.

\section{Conclusões}

Concluímos que o projeto da interface foi bem-sucedido, e que a combinação entre o uso de atributos espectrais e de um wrapper progressivo é promissora para a construção de dispositivos baseados em imaginação de movimento.

\section{Agradecimentos}

Agradecemos ao PIBIC e ao CNPq o apoio financeiro.

\footnotetext{
${ }^{1}$ Wolpaw, J. R., Birbaumer, N., McFarland D. J., Pfurtscheller, G. e Vaughan, T. M. "Brain-computer interfaces for communication and control" Clinical Neurophysiology, 2002, Vol. 113, pp. $767-791$.

${ }^{2}$ Leite, S. N. C., "Contribuições ao Desenvolvimento de Interfaces CérebroComputador Baseadas em Potenciais Evocados Visualmente em Regime Estacionário", 2016, Tese de Doutorado, UNICAMP.

${ }^{3}$ Dornhege, G., Millán, J. R., Hinterberger, T., McFarland, D. J., Müller, K.R., Toward Brain-Computer Interfacing, 2007, MIT Press.
} 